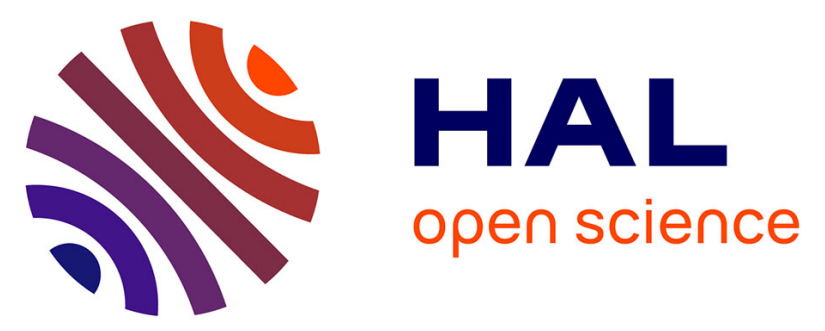

\title{
Measurement of Indoleamine 2, 3 Dioxygenase Activity in Colorectal Cancer: A Controlled Group Study
}

Daniel Eyraud, Benjamin Granger, Noel Zahr, Frédéric Charlotte, Armelle Bardier, Gaëlle Gottrand, Audrey Perez-Lascar, Mehdi Karoui, Louis Lemoine, Jean Christophe Vaillant, et al.

\section{To cite this version:}

Daniel Eyraud, Benjamin Granger, Noel Zahr, Frédéric Charlotte, Armelle Bardier, et al.. Measurement of Indoleamine 2, 3 Dioxygenase Activity in Colorectal Cancer: A Controlled Group Study. Journal of Clinical and Cellular Immunology, 2015, 06 (06), pp.1000374. 10.4172/2155-9899.1000374 . hal-01910154

\section{HAL Id: hal-01910154 https: / hal.sorbonne-universite.fr/hal-01910154}

Submitted on 31 Oct 2018

HAL is a multi-disciplinary open access archive for the deposit and dissemination of scientific research documents, whether they are published or not. The documents may come from teaching and research institutions in France or abroad, or from public or private research centers.
L'archive ouverte pluridisciplinaire HAL, est destinée au dépôt et à la diffusion de documents scientifiques de niveau recherche, publiés ou non, émanant des établissements d'enseignement et de recherche français ou étrangers, des laboratoires publics ou privés. 


\title{
Journal of Clinical \& Cellular Immunology
}

\section{Measurement of Indoleamine 2, 3 Dioxygenase Activity in Colorectal Cancer: A Controlled Group Study}

Daniel Eyraud ${ }^{1-3}$, Benjamin Granger ${ }^{4}$, Noel Zahr5, Frédéric Charlotte ${ }^{6}$, Armelle Bardier ${ }^{6}$, Gaëlle Gottrand ${ }^{3}$, Audrey Perez-Lascar ${ }^{3}$, Mehdi Karoui ${ }^{2}$, Louis Lemoine $^{1}$, Jean Christophe Vaillant ${ }^{2}$, David Klatzmann ${ }^{3}$, Laurent Hannoun ${ }^{2}$ and Pierre Coriat ${ }^{1}$

${ }^{1}$ Department of Anesthesiology and Reanimation, Assistance Publique-Hôpitaux de Paris (AP-HP), Pitié-Salpêtrière University Hospital, 43-87 Boulevard de l'Hôpital, 75013 Paris, France

${ }^{2}$ Department of Digestive and HPB Surgery, Assistance Publique-Hôpitaux de Paris (AP-HP), Pitié-Salpêtrière University Hospital, $43-87$ Boulevard de l'Hôpital, 75013 Paris, France

${ }^{3}$ Department of Biotherapies CNRS 7211 INSERM 959, Assistance Publique-Hôpitaux de Paris (AP-HP), Pitié-Salpêtrière University Hospital, 43-87 Boulevard de l'Hôpital, 75013 Paris, France

${ }^{4}$ Department of statistics, Clinical Research Unit, Assistance Publique-Hôpitaux de Paris (AP-HP), Pitié-Salpêtrière University Hospital, 43-87 Boulevard de l'Hôpital, 75013 Paris, France

${ }^{5}$ Department of Clinical Pharmacology, Assistance Publique-Hôpitaux de Paris (AP-HP), Pitié-Salpêtrière University Hospital, $43-87$ Boulevard de l'Hôpital, 75013 Paris, France

${ }^{6}$ Department of histology and UIMAP, Assistance Publique-Hôpitaux de Paris (AP-HP), Pitié-Salpêtrière University Hospital, $43-87$ Boulevard de l'Hôpital, 75013 Paris, France

"Corresponding author: Daniel Eyraud, Assistance Publique-Hôpitaux de Paris (AP-HP), Pitié-Salpêtrière University Hospital, Department of Anesthesiology and Reanimation, 43-87 Boulevard de l'Hôpital, 75013 Paris, France, Tel: 003314217 58 65; Fax: 00331421756 13; E-mail: daniel.eyraud@psl.ap-hop-paris.fr

Received date: September 21, 2015; Accepted date: November 28, 2015; Published date: December 08, 2015

Copyright: ๑ 2015 Eyraud D, et al. This is an open-access article distributed under the terms of the Creative Commons Attribution License, which permits unrestricted use, distribution, and reproduction in any medium, provided the original author and source are credited.

\begin{abstract}
Background: Indoleamine 2,3-dioxygenase (IDO), the rate-limiting enzyme that converts tryptophan (Trp) to kynurenine (Kyn), suppresses antitumor immune responses via depletion of Trp and accumulation of Kyn. We hypothesized that, in colorectal cancer (CRC), IDO activity may serve as a biomarker and thus we compared the IDO activity between patients with CRC and those without CRC. We further assessed the effect of surgical treatment of CRC on IDO activity.
\end{abstract}

Methods: Serum concentrations of Trp and Kyn were measured by high performance liquid chromatography in the sera of 68 patients with CRC (CRC group) and 38 without CRC (Control group) prior surgery (D0) and 7 days after surgery (D7). The IDO activity was estimated by the serum Kyn-to-Trp ratio (Kyn/Trp ratio).

Results: At Day 0, serum Kyn concentration was higher in the CRC group than in Control group $(1.7$ [1.4;2.1] $\mu \mathrm{M}$ vs $1.25[0.9 ; 1.78] \mu \mathrm{M}$, respectively; $\mathrm{p}=0.004)$ while no difference in serum concentration of Trp was observed between the two groups. Kyn/Trp ratio (IDO activity) was significantly higher in the CRC group than in Control group. At Day 7 serum concentrations of Trp, Kyn and the Kyn/Trp ratio were not statistically different between the two groups.

Conclusion: This study indicates that IDO activity is higher in patients with CRC compared with those without CRC. Surgical treatment impacts the IDO activity with a similar Kyn/Trp ratio in both groups. This study is the first step to larger studies to establish the Kyn/Trp ratio as a reliable serum marker of CRC.

Keywords: Indoleamine 2,3 - dioxygenase activity; Biomarker; Colorectal cancer; Kynurénine; Serum concentration

\section{Introduction}

Indoleamine 2,3-dioxygenase (IDO) is the rate-limiting enzyme that catalyzes the conversion of tryptophan (Trp) to kynurénine (Kyn) [1]. IDO has been implicated in the suppression of the antitumor immune responses trough depletion of Trp and accumulation of Trp metabolites [2,3]. Several studies have shown that this activation of tryptophan metabolism by IDO suppresses T-cell proliferation and promotes T-cell apoptosis in the tumor tissue. Consistently, increased IDO activity have been reported in several types of cancers such as skin [4] breast [5] and lung cancer [6] and have even been associated with disease progression and poor prognosis in lung [6] and skin cancer [4]. In these cancers, the measurement of Kyn and Trp concentration and calculation of the Kyn/Trp ratio have been used as surrogate indicators of IDO activity.

The role of IDO activity in colorectal cancer (CRC) is, however, not yet well-defined. Data from experimental study indicate that IDO prevent the development of colorectal cancer driven by chronic inflammation [7]. Indeed, IDO deficiency in chronic inflammatory disease models increased the incidence of colonic tumor. By contrast, IDO expression in human colorectal tumors has been involved in CRC progression $[8,9]$. These conflicting results suggest that more data are needed on IDO activity in colorectal cancer to determine whether activation of tryptophan catabolism by IDO may serve as a biomarker of CRC. Therefore, this study aimed at comparing the IDO activity 
between patients with CRC and those without CRC, by measuring the serum concentration of Kyn and Trp and calculating Kyn/Trp ratio.

Furthermore, to define the impact of therapy on IDO activity, the serum concentration of Kyn and Trp was assessed prior surgical resection and post-operatively in all the patients included in this study that were scheduled to undergo surgical resection either for CRC or for benign colorectal disease.

\section{Methods}

\section{Patients}

This prospective longitudinal observational study was conducted in a single institution, Pitié-Salpêtrière Hospital, Paris, France. Eligible patients were scheduled to undergo surgical resection of either a primary colon cancer (CRC group) or of a benign colon disease (Control group). Patients were excluded if they had received neoadjuvant chemotherapy or radiotherapy or if they had a diagnosis of concomitant cancer. Patients with chronic renal disease or receiving medications that interfere with Trp metabolism were also excluded. No patients had autoimmune diseases, viral hepatitis, or human immunodeficiency virus (HIV) infection.

This study was approved by the Independent Ethics Committee of Pitié-Salpêtrière Hospital. All patients provided written informed consent before participation.

\section{Clinical and histologic evaluation}

Histopathological and clinical findings were scored according to the tumor-node-metastasis (TNM) staging system of the UICC [10]. Early metastatic invasion was assessed by the presence of vascular emboli, lymphatic invasion, and perineural invasion (VELIPI) alone or in combination. A VELIPI-positive tumor was defined by the presence of at least one of these pathological findings, whereas a VELIPInegative tumor had none of the three findings [11]. Microsatellite instability (MSI) was assessed by performing immuno-histo-chemichal staining for $M L H 1, M S H 2$ and $M S H 6$.

\section{Immunohistochemistry}

The immuno-staining procedure was performed on formalin-fixed, deparaffinised $4-\mu \mathrm{m}$ thick TMA sections by using a biotin-free polymeric visualization system (Ultravison LP ref TL-015-HD, Lab Vision, Fremont, CA, USA). The primary mouse monoclonal anti-IDO antibody (clone 10.1, Chemicon-Millipore, Molsheim, France), dilution 1:100 were used at the indicated dilutions. The antigen retrieval reaction was performed in a water bath, using EDTA buffer ( $\mathrm{pH} \mathrm{8.0)} \mathrm{for} 20 \mathrm{~min}$ at $97^{\circ} \mathrm{C}$. The slides were then incubated with the peroxidase block supplied by the manufacturer of the visualization system for $10 \mathrm{~min}$. Next, the slides were incubated with the primary antibodies for $60 \mathrm{~min}$ at room temperature. The incubation time was $10 \mathrm{~min}$ for each step of the visualization system. Chromogen diaminobenzidine supplied by the manufacturer was applied for $5 \mathrm{~min}$, and counterstaining with haematoxylin for $1 \mathrm{~min}$.

\section{Laboratory examination}

Serum samples of patients were collected prior surgical resection on the day of surgery (Day 0) and seven days after surgery (Day 7). Serum samples were frozen at $-70^{\circ} \mathrm{C}$ until analysis.
The concentrations of Trp and Kyn were measured simultaneously by high performance liquid chromatography (HPLC) equipment with UV detection setting at $360 \mathrm{~nm}$ for Kyn, and at $278 \mathrm{~nm}$ for Trp in a single run according to Yamada et al. [12].

\section{Statistical analysis}

The primary evaluation criterion was the serum Kyn concentration measured prior surgery (D0). The study was designed to have a power of $80 \%$ to detect a clinically significant difference of 0.5 (0.8 of standard deviation) at a $5 \%$ level of significance (two-sided test) with a ratio of 2:1 for CRC group and Control group. Based on this assumption, 62 and 31 patients should be included in the CRC group and the Control group, respectively.

Data were expressed as median [first quartile; third quartile] for continuous data and as frequency (percentage) for categorical data. Longitudinal data are graphically represented as a plot group means and confidence intervals and as spaghetti plot.

For Kyn concentration, Trp concentration and Kyn/Trp ratio: the "group effect" (CRC vs. control) was assessed using Wilcoxon rank sum test for continuous variables. The "time effect" (comparison between pre- and post-operative) was assessed using Wilcoxon rank sum test for paired data. The possible correlations between serum Kyn concentration and serum Trp concentration at D0 and D7 were assessed by using Spearman's rank correlation technique.

The associations between baseline characteristics and group were assessed with Fisher's exact test or Wilcoxon rank sum test according to the tested covariate.

The association between tumor characteristics and serum Kyn concentration or Kyn/trp ratio was assessed by Wilcoxon rank sum test or Kruskal Wallis rank sum test.

Then receiver operating characteristic (ROC) curve analysis was performed to determine the best discriminative point, distinguishing CRC group and Control group at baseline.

\section{Results}

\section{Patient and tumor characteristics}

A total of 106 patients were included in this study: 68 patients in the CRC group and 38 in the Control group. Patient and tumor characteristics are shown in Table 1. Demographic characteristics were comparable between the two groups. In the Control group, all the patients had a left colonic resection for diverticulitis. In the CRC group, about $75 \%$ of patients had a T3 or T4 tumors and 38 patients (55\%) had VELIPI positive-tumor. High level of MSI (MSI-H), that is associated with a favorable prognosis, was detected in 9\%. All 27 tumors analyzed with immuno-staining procedure was IDO positive (Figure 1).

\section{Serum concentrations of Trp and Kyn and Kyn/Trp ratio}

The concentrations of Trp, Kyn, and the Kyn/Trp ratio prior surgical resection (Day 0) and seven days after surgery (Day 7 ) are presented in Table 2. At Day 0, the serum concentration of Kyn and the Kyn/Trp ratio were significantly higher in the CRC group than in the Control group. 
Citation: Eyraud D, Granger B, Zahr N, Charlotte F, Bardier A, et al. (2015) Measurement of Indoleamine 2, 3 Dioxygenase Activity in Colorectal Cancer: A Controlled Group Study. J Clin Cell Immunol 6: 374. doi:10.4172/2155-9899.1000374

Page 3 of 8

\begin{tabular}{|c|c|c|c|}
\hline & $\begin{array}{l}\text { CRC group } \\
N=68\end{array}$ & $\begin{array}{l}\text { Control group } \\
\mathrm{N}=38\end{array}$ & p \\
\hline $\begin{array}{l}\text { Age (years), mean } \pm \\
\text { SD }\end{array}$ & $\begin{array}{l}64.89 \quad[55.93 ; \\
75.73]\end{array}$ & $\begin{array}{l}61.43 \quad[52.18 ; \\
66.36]\end{array}$ & $0.604^{*}$ \\
\hline Male, n (\%) & $40(59)$ & $23(61)$ & $1^{\circ}$ \\
\hline \multicolumn{4}{|l|}{ Tumor (T) stage } \\
\hline pT1 & $4(6)$ & & \\
\hline pT2 & $10(15)$ & & \\
\hline pT3 & $38(58)$ & & \\
\hline pT4 & $14(21)$ & & \\
\hline \multicolumn{4}{|l|}{ Nodal (N) stage } \\
\hline No & $33(51)$ & & \\
\hline N1 & $17(26)$ & & \\
\hline N2 & $15(23)$ & & \\
\hline \multicolumn{4}{|l|}{ Metastatic } \\
\hline M0 & $47(72)$ & & \\
\hline M1 & $18(28)$ & & \\
\hline \multicolumn{4}{|l|}{ VELIPI } \\
\hline Vascular emboli & $12(19)$ & & \\
\hline Lymphatic invasion & $29(45)$ & & \\
\hline Perineural invasion & $18(28)$ & & \\
\hline MSI-H & $5(9)$ & & \\
\hline Stenosis & $31(47)$ & & \\
\hline \multicolumn{4}{|c|}{$\begin{array}{l}\text { Continuous data are expressed as median [first quartile; third quartile], } \\
\text { categorical data expressed as number (\%) otherwise specify. *Wilcoxon rank } \\
\text { sum test; }{ }^{\circ} \text { Fisher's exact test }\end{array}$} \\
\hline
\end{tabular}

Table 1: Patients' characteristics.

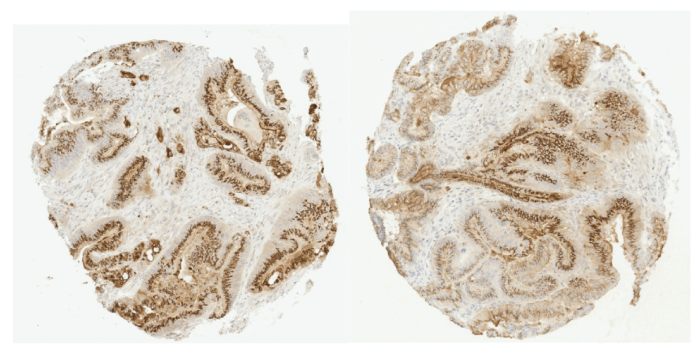

Figure 1: Expression of IDO in colorectal adenocarcinoma on TMA spots. In these examples, the tumor cells positive for IDO showed a brown cytoplasmic immunostaining (Immunoperoxidase, original magnification $\mathrm{x} 100)$.

\begin{tabular}{|c|c|c|c|c|c|}
\hline & & $\begin{array}{l}\text { Pre- } \\
\text { operative } \\
\text { D0 }\end{array}$ & $\begin{array}{l}\text { Post- } \\
\text { operative } \\
\text { D7 }\end{array}$ & $\Delta$-Do & $\begin{array}{l}P \text { (Time } \\
\text { effect) }\end{array}$ \\
\hline \multirow[t]{3}{*}{$\begin{array}{l}\text { Kynurenine } \\
(\mu \mathrm{mol} / \mathrm{L})\end{array}$} & CRC & $\begin{array}{l}1.7 \\
{[1.4 ; 2.1]}\end{array}$ & $\begin{array}{l}2 \\
{[1.5 ; 2.6]}\end{array}$ & $\begin{array}{l}0.3 \\
{[-0.2 ; 1]}\end{array}$ & $<0.001$ \\
\hline & Control & $\begin{array}{l}1.25 \\
{[0.9 ; 1.78]}\end{array}$ & $\begin{array}{l}1.5 \\
{[1.2 ; 2.42]}\end{array}$ & $\begin{array}{l}0.35 \\
{[0.07 ; 0.9]}\end{array}$ & 0.002 \\
\hline & $\begin{array}{l}\text { P } \\
\text { (group } \\
\text { effect) }\end{array}$ & 0.004 & 0.118 & 0.615 & \\
\hline \multirow[t]{3}{*}{$\begin{array}{l}\text { Tryptophan } \\
(\mu \mathrm{mol} / \mathrm{L})\end{array}$} & CRC & $\begin{array}{l}31.4 \\
{[26 ; 38.2]}\end{array}$ & $\begin{array}{l}34 \\
{[29.3 ; 42.4]}\end{array}$ & $\begin{array}{l}2.1 \\
{[-4.8 ; 12.1]}\end{array}$ & 0.057 \\
\hline & Control & $\begin{array}{l}31.8 \\
{[27.92 ;} \\
41.5]\end{array}$ & $\begin{array}{l}34.6 \\
{[27 ; 38.55]}\end{array}$ & $\begin{array}{l}1.25 \\
{[-7 ; 5.83]}\end{array}$ & 0.918 \\
\hline & $\begin{array}{l}\text { P } \\
\text { (group } \\
\text { effect) }\end{array}$ & 0.744 & 0.651 & 0.328 & \\
\hline \multirow[t]{3}{*}{ Kyn/Trp } & CRC & $\begin{array}{l}0.05 \\
{[0.04 ; 0.6]}\end{array}$ & $\begin{array}{l}0.06 \\
{[0.04 ; 0.7]}\end{array}$ & $\begin{array}{l}0.01 \\
{[-0.01 ; 0.02]}\end{array}$ & 0.131 \\
\hline & Control & $\begin{array}{l}0.04 \\
{[0.03 ; 0.05]}\end{array}$ & $\begin{array}{l}0.05 \\
{[0.04 ; 0.06]}\end{array}$ & $\begin{array}{l}0.01 \\
{[0 ; 0.02]}\end{array}$ & 0.003 \\
\hline & $\begin{array}{l}\text { P } \\
\text { (group } \\
\text { effect) }\end{array}$ & $<0.001$ & 0.223 & 0.164 & \\
\hline $\begin{array}{l}\text { oup effe } \\
\text { aired data }\end{array}$ & Nilcos & sum test & ne effect $V$ & oxon rank & $n$ test for \\
\hline
\end{tabular}

Table 2: Serum tryptophan, kynurenine and the kynurenine-totryptophan ratio (kyn/ trp) in patients with CRC (CRC) and without CRC (Control) at D0 and D7. Data are expressed as median [first quartile ; third quartile].

At Day 7, the serum concentrations of Kyn and the Kyn/Trp ratio were not statistically different between the two groups. Indeed, the concentration of Kyn was significantly increased 7 days after surgery in the two groups.

The increase of Kyn concentration from Day 0 to Day 7 was comparable in the CRC group and in the Control group as illustrated in Figure 2. Concurrently, no significant changes from Day 0 to Day 7 in the Trp concentration were observed in both groups (Figure 2).

\section{Correlation between Kynurénine and Tryptophan serum concentrations}

The correlation between Kyn and Trp concentrations at Day 0 and at Day 7 in the CRC group are shown in Figure 3. Prior surgery, we observed a significant positive correlation between the Kyn and Trp concentrations. This positive correlation between these two parameters remained after the surgical resection of CRC (Day7). In the control group, we also observed significant correlation between Kyn and Trp concentrations at Days $0(\mathrm{r}=0.5, \mathrm{p}=0.001)$ and Day $7(\mathrm{r}=0.52, \mathrm{p}=0.002)$. 
Citation: Eyraud D, Granger B, Zahr N, Charlotte F, Bardier A, et al. (2015) Measurement of Indoleamine 2, 3 Dioxygenase Activity in Colorectal Cancer: A Controlled Group Study. J Clin Cell Immunol 6: 374. doi:10.4172/2155-9899.1000374

Page 4 of 8

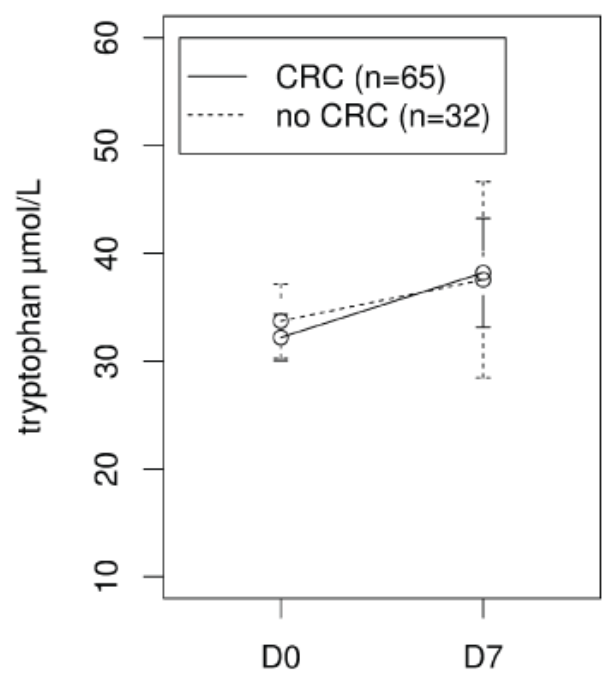

visit

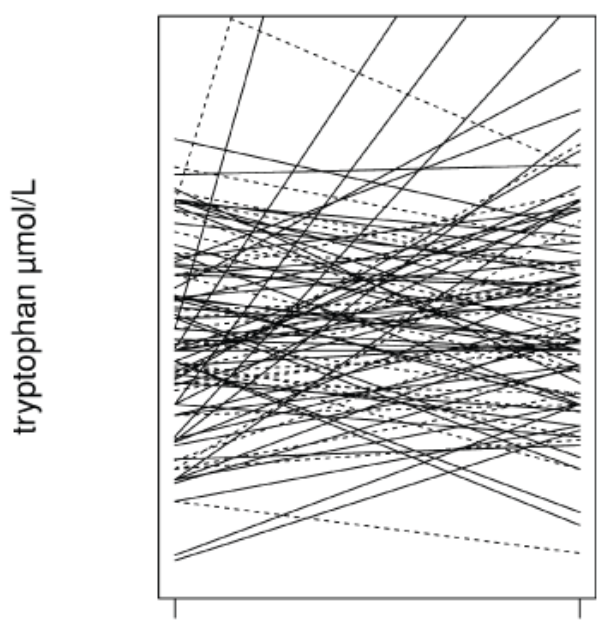

D0
D7

visit

A

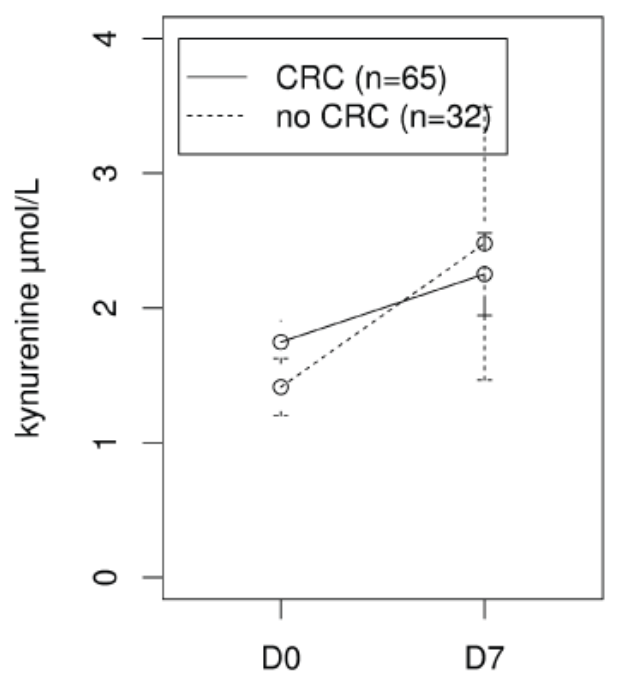

visit

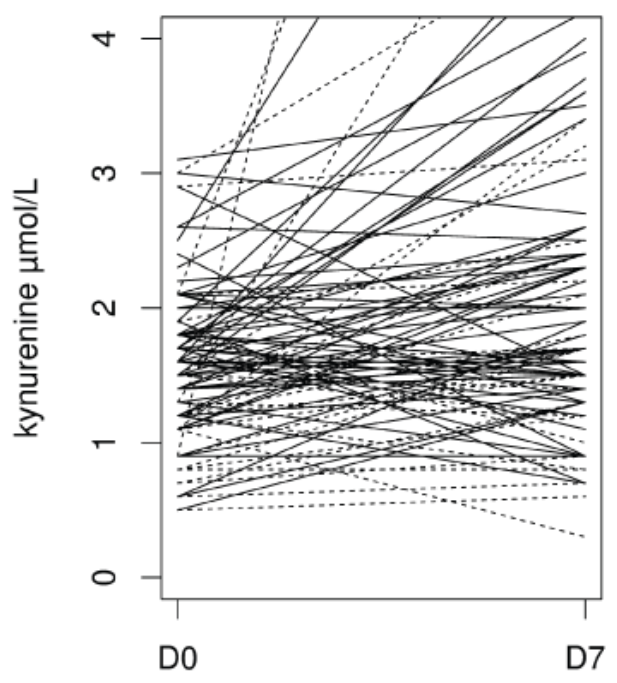

Visit

B

Figure 2: Change in serum kynurenine (Figure 2A) and tryptophan (Figure 2B) concentration between D0 (prior surgery) and D7 (7 days after surgery). The parameter is expressed as mean and $95 \%$ confidence interval (left panel) and as spaghetti plot (right panel). 
Citation: Eyraud D, Granger B, Zahr N, Charlotte F, Bardier A, et al. (2015) Measurement of Indoleamine 2, 3 Dioxygenase Activity in Colorectal Cancer: A Controlled Group Study. J Clin Cell Immunol 6: 374. doi:10.4172/2155-9899.1000374

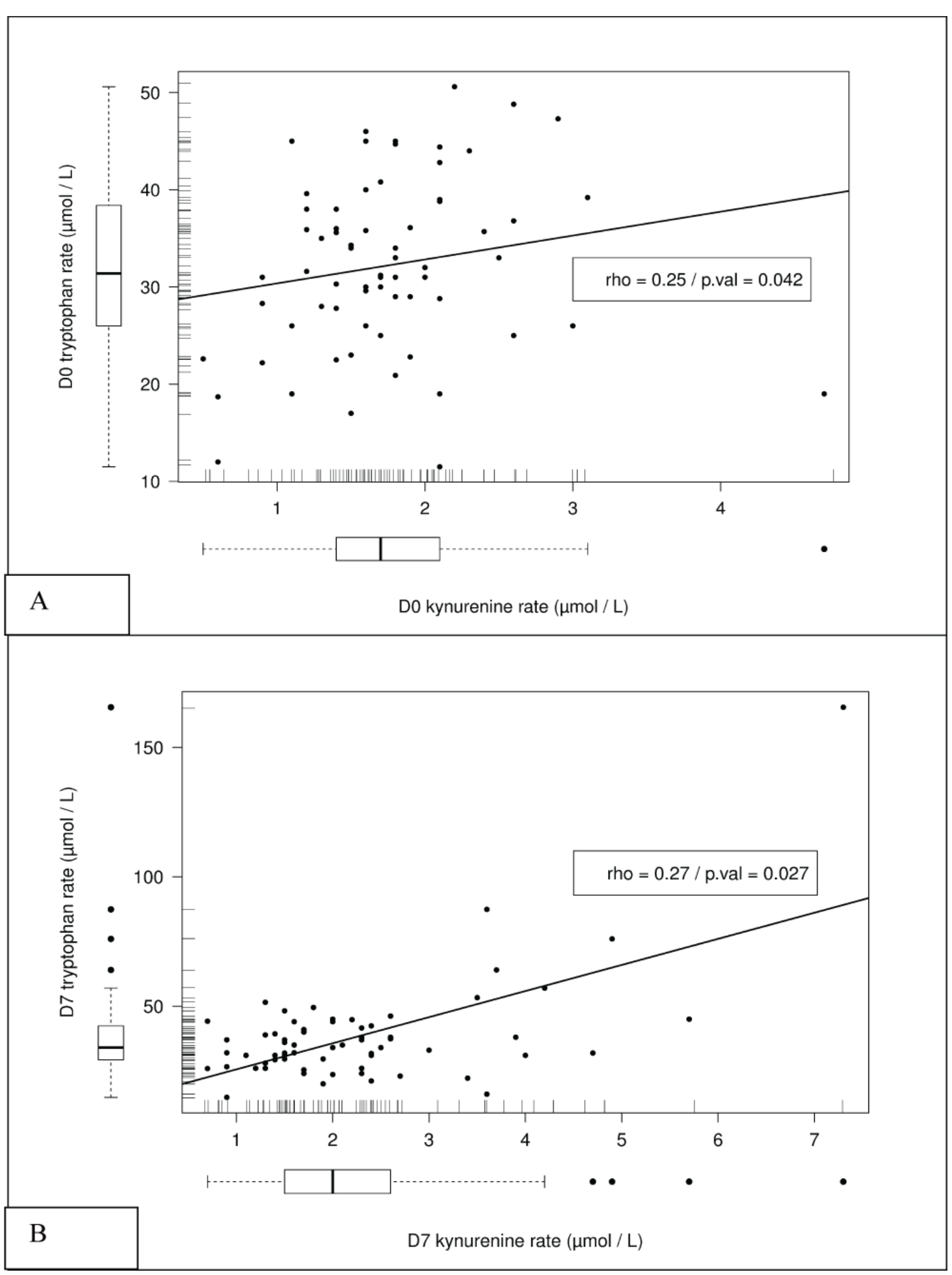

Figure 3: Cartesian diagram and regression line between serum kynurenine and tryptophan concentrations in CRC patients at D0 (prior surgery) (Figure 3A) and D7 (7 days after surgery) (Figure 3B). Box plot and individual values are represented along the axes. Correlation (spearman rho and p-value) appears in the box. 


\section{Association between the concentrations of Kyn and Trp and tumor characteristics}

Of all the tumor characteristics assessed individually in the univariate analysis, none were found to be significantly associated with the serum concentration of Kyn or the Kyn/Trp ratio measured prior surgery (Table 3). Similar results were observed for the serum concentration of Trp.

\begin{tabular}{|c|c|c|c|c|}
\hline \multirow{2}{*}{$\begin{array}{l}\text { Tumor } \\
\text { characteristics }\end{array}$} & \multicolumn{2}{|c|}{ Kynurenine ( $\mu \mathrm{mol} / \mathrm{L}$ ) } & \multicolumn{2}{|l|}{ Kyn/Trp } \\
\hline & Mean \pm SD & $\mathbf{p}$ & Mean \pm SD & $\mathbf{p}$ \\
\hline \multicolumn{5}{|l|}{$T^{*}$} \\
\hline T1 & 1.95 & 0.332 & $\begin{array}{l}0.045 \quad[0.035 ; \\
0.053]\end{array}$ & 0.770 \\
\hline T2 & $\begin{array}{l}1.55 \quad[1.10 ; \\
1.78]\end{array}$ & & $0.05[0.04 ; 0.06]$ & \\
\hline T3 & $\begin{array}{l}1.75 \quad[1.43 ; \\
2.10]\end{array}$ & & $0.05[0.04 ; 0.06]$ & \\
\hline $\mathrm{T} 4$ & $\begin{array}{l}1.55 \quad[1.40 ; \\
1.90]\end{array}$ & & $0.05[0.04 ; 0.07]$ & \\
\hline \multicolumn{5}{|l|}{$\mathbf{N}^{*}$} \\
\hline No & $1.7[1.4 ; 2.1]$ & 0.447 & $0.05[0.04 ; 0.06]$ & 0.500 \\
\hline N1 & $1.6[1.1 ; 1.8]$ & & $0.04[0.04 ; 0.07]$ & \\
\hline N2 & $1.8[1.5 ; 2]$ & & $\begin{array}{l}0.05 \quad[0.045 ; \\
0.065]\end{array}$ & \\
\hline \multicolumn{5}{|l|}{$\mathbf{M}^{\circ}$} \\
\hline MO & $1.7[1.4 ; 2.1]$ & 0.654 & $0.05[0.04 ; 0.06]$ & 0.709 \\
\hline M1 & $1.75[1.23 ; 1.9]$ & & $\begin{array}{l}0.045 \\
0.068]\end{array} \quad[0.04$ & \\
\hline \multicolumn{5}{|l|}{ VELIPI } \\
\hline & $1.8[1.18 ; 2.13]$ & 0.966 & $0.04[0.04 ; 0.075]$ & 0.895 \\
\hline & $1.7[1.4 ; 2.1]$ & 0.995 & $0.05[0.04 ; 0.06]$ & 0.805 \\
\hline Perineural invasion & $1.6[1.43 ; 2.05]$ & 0.905 & $0.05[0.04 ; 0.058]$ & 0.698 \\
\hline MSI-H' & $1.7[1.6 ; 1.7]$ & 0.745 & $0.04[0.04 ; 0.05]$ & 0.336 \\
\hline Stenosis $^{\circ}$ & $1.7[1.4 ; 1.9]$ & 0.8822 & $0.05[0.04 ; 0.07]$ & 0.719 \\
\hline $\begin{array}{l}\text { Continuous data are } \\
\text { *Kruskal-Wallis rank } \\
{ }^{\star} \text { Wilcoxon rank sum }\end{array}$ & $\begin{array}{l}\text { expressed as me } \\
\text { sum test } \\
\text { test }\end{array}$ & dian [first & artile; third quartile] & \\
\hline
\end{tabular}

Table 3: Association between tumor characteristics and activation of tryptophan metabolism in patients with CRC.

\section{Receiver operating characteristic (ROC) curve analysis}

A sensitivity-specificity analysis of serum kynurenine levels in distinguishing CCR group from Control group was performed (Figure 4). The best discriminative point was 1.51 (sensitivity=0.63; specificity=0.68).

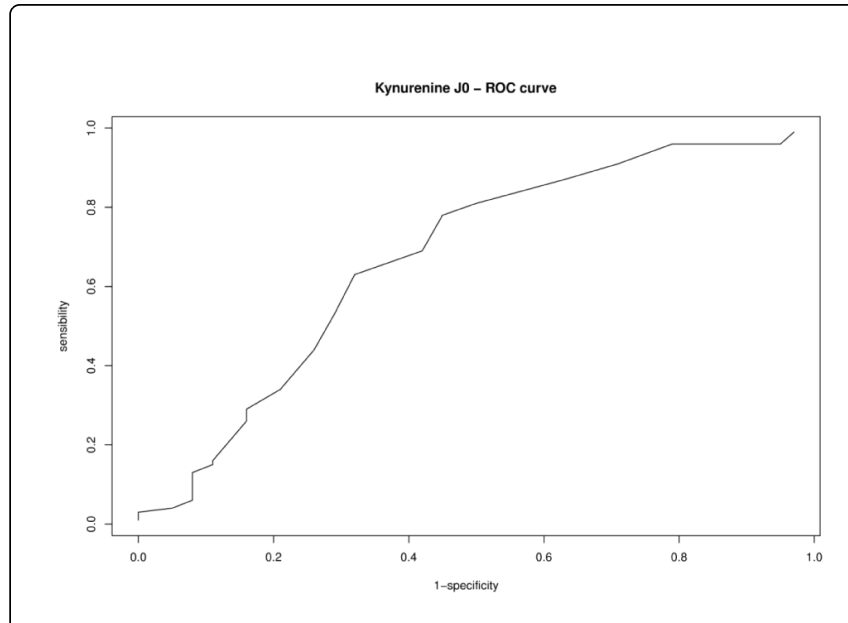

Figure 4: Receiver operating characteristic (ROC) curve analysing the sensitivity and specificity of serum kynurenine levels at Day 0 (J0) distinguishing colorectal cancer group from Control. The best discriminative point was 1.51 (sensitivity $=0.63$; specificity $=0.68$ ).

\section{Discussion}

The results of this study indicate that IDO activity assessed by serum Kyn/Trp ratio is higher in patients with CRC compared with those without CRC before the surgical removal of the CCR. Furthermore, our data show that the treatment of colorectal cancer impacts the IDO activity since the Kyn/Trp ratio in patients with CRC after removal of colorectal cancer was similar to that of patients with benign colorectal disease. Altogether, our results suggest that increased serum Kyn/Trp ratio may be linked to CRC.

These results are in line with previous studies indicating that IDO is expressed in colorectal carcinoma [3,8,9]. In some of these studies, IDO expression levels significantly correlated with the reduction in intra-tumoral $\mathrm{T}$ cells, the presence of distant metastases and overall survival in patients with colorectal cancer $[8,9]$.

Only few studied have analyzed the IDO plasma activity, defined as the Kyn/Trp ratio, in cancer disease: Suzuki et al. [6] in lung cancer, Weinlich et al. [4] in melanoma, Lyon et al. [5] in breast cancer and Cavia-Saiz et al. [15] in colorectal cancer in response to chemotherapy. Our results, are comparable with those of the three first cited studies: plasma IDO activity is increased in patients with cancer compared with healthy volunteers. Lyon et al. interested in plasma IDO activity in patients with CCR: they observed that all patients with CCR had elevated IDO activity in plasma and in dendritic cells [5]. Instead of studying the plasma IDO activity in response to the surgery, as in our study, they studied the plasma IDO activity in response to chemotherapy and showed that the plasma IDO activity after chemotherapy in CCR group was similar to plasma IDO activity in the healthy group. The design of the study did not allow concluding if the decrease of the plasma IDO activity was in relation with the decrease of the cancer size or with the chemotherapy. In contrast, in our study, because the two groups was submitted to the same anesthesia, surgery and perioperative care, the intrinsic effect of the treatment is the same: if IDO activity is not significantly different after surgery whereas it was significantly different before, it can be a priori attributed to the 
decrease in cancer mass in relation with the surgery. An important limitation however could be the important inflammatory effect of the surgery we detail after.

However, in our study, we did not find any association between the serum Kyn concentration or the Kyn/Trp ratio and the tumor characteristics, i.e., TNM, early metastatic invasion assessed by VELIPI and MSI status. This difference may be explained by the fact that in the aforementioned studies, the protein expression of IDO was detected solely in the tumor tissue whereas in our study the ratio of Kyn to Trp was measured in patient's plasma. Serum concentrations of Kyn and Trp may be affected by confounding effects such as concurrent medication, nutritional state or unspecific inflammation. Indeed, IDO may be induced by unspecific inflammation as $I D O$ is a very sensitive IFN $\gamma$ response gene [13]. Beside IDO, the systemic Trp levels are also regulated by tryptophan-2,3-dioxygenase (TDO) and are closely related to dietary intake [14]. These factors may account for the absence of difference in serum Trp concentration between patients with CRC and those with benign colorectal disease observed in our study.

We further assessed the change in IDO activity in response to CRC resection. Seven days after surgery, the serum Kyn/Trp ratio was comparable between patients with CRC and those without CRC, suggesting a close relationship between IDO activity and CRC. In line with this finding, a decrease of IDO activity has been reported in patients with CRC after chemotherapy [15]. However, our result should be interpreted with caution. Indeed, after surgery, we also observed an increase in serum Kyn concentration in both patients with CRC and those with benign colorectal disease. This increase may be attributed to surgery as surgery or trauma leads to an inflammatory response involving pro-inflammatory cytokines such as IFN $\gamma$ that could activate tryptophan catabolism [16]. Consistently, a higher serum Kyn/Trp ratio, lower Trp concentration and concomitant increase in Kyn concentration have been reported in trauma patients compared to healthy volunteers [17]. In our study, the surgical treatment per se may thus have impacted the estimation of IDO activity after the removal of colorectal cancer. In addition, 23 of 68 patients with CRC had metastasis, which could explain the absence of change in Trp concentration post-operatively. Altogether, this suggests that the measurement of serum Kyn -Trp concentration at lesser level, and calculation of $\mathrm{Kyn} / \mathrm{Trp}$ ratio could be considered for further studies as biomarkers to monitor the response to the surgical treatment of CRC.

This study had some limitations. Taking into account that surgery triggers an inflammatory response, we could have assessed proinflammatory cytokines in patient's plasma. In addition, the Control group was constituted by patients with diverticulitis, even though elective colectomy was performed after recovery from acute diverticulitis. However, the serum concentrations of Kyn and Trp in these patients were similar to those reported in healthy volunteers in previous studies [6]. Moreover, the postoperative sampling at Day 7, before the hospital's discharge, is from a distance of the inflammatory postoperative phase.

\section{Conclusion}

In summary, this study shows that IDO activity measured by the Kyn/Trp was higher in patients with CRC than in patients without CRC. After the removal of the primary colorectal cancer- and then of the whole or the majority of the tumor mass- IDO activity was similar in both groups, suggesting that the Kyn/Trp ratio might be a marker of CRC. Thus, because our findings suggest that IDO activity is related to CRC, further studies are needed to establish the Kyn/Trp ratio as a reliable serum marker of CRC.

\section{Acknowledgement}

We thank Nathalie Nunes for technical assistance.

\section{Conflict of Interest}

The authors have not declared any conflicts of interests.

\section{Funding}

Dr Eyraud received a grant of the association of research in surgery ARCEC (43-87 Boulevard de l'Hôpital 75013 Paris, France).

\section{References}

1. Stone TW, Darlington LG (2002) Endogenous kynurenines as targets for drug discovery and development. Nat Rev Drug Discov 1: 609-620.

2. Mellor AL, Keskin DB, Johnson T, Chandler P, Munn DH (2002) Cells expressing indoleamine 2,3-dioxygenase inhibit $\mathrm{T}$ cell responses. J Immunol 168: 3771-3776.

3. Uyttenhove C, Pilotte L, Théate I, Stroobant V, Colau D, et al. (2003) Evidence for a tumoral immune resistance mechanism based on tryptophan degradation by indoleamine 2,3-dioxygenase. Nat Med 9: 1269-1274.

4. Weinlich G, Murr C, Richardsen L, Winkler C, Fuchs D (2007) Decreased serum tryptophan concentration predicts poor prognosis in malignant melanoma patients. Dermatology 214: 8-14.

5. Lyon DE, Walter JM, Starkweather AR, Schubert CM, McCain NL (2011) Tryptophan degradation in women with breast cancer: a pilot study. BMC Res Notes 4: 156.

6. Suzuki Y, Suda T, Furuhashi K, Suzuki M, Fujie M, et al. (2010) Increased serum kynurenine/tryptophan ratio correlates with disease progression in lung cancer. Lung Cancer 67: 361-365.

7. Chang MY, Smith C, DuHadaway JB, Pyle JR, Boulden J, et al. (2011) Cardiac and gastrointestinal liabilities caused by deficiency in the immune modulatory enzyme indoleamine 2,3 - dioxygenase. Cancer Biol Ther 12: 1050-1058.

8. Brandacher G, Perathoner A, Ladurner R, Schneeberger S, Obrist P, et al. (2006) Prognostic value of indoleamine 2,3-dioxygenase expression in colorectal cancer: effect on tumor-infiltrating T cells. Clin Cancer Res 12: 1144-1151.

9. Ferdinande L, Decaestecker C, Verset L, Mathieu A, Moles Lopez X, et al. (2012) Clinicopathological significance of indoleamine 2,3-dioxygenase 1 expression in colorectal cancer. Br J Cancer 106: 141-147.

10. Sobin LH, Gospodarowicz MK, Wittekind C (2009) TNM classification of malignant tumors. (7thedn), John Wiley \& Sons, New-York.

11. Pagès F, Berger A, Camus M, Sanchez-Cabo F, Costes A, et al. (2005) Effector memory $\mathrm{T}$ cells, early metastasis, and survival in colorectal cancer. N Engl J Med 353: 2654-2666.

12. Zhang X, He Y, Ding M (2009) Simultaneous determination of tryptophan and kynurenine in plasma samples of children patients with Kawasaki disease by high-performance liquid chromatography with programmed wavelength ultraviolet detection. J Chromatogr B Analyt Technol Biomed Life Sci 877: 1678-1682.

13. Taylor MW, Feng GS (1991) Relationship between interferon-gamma, indoleamine 2,3 - dioxygenase, and tryptophan catabolism. FASEB J 5: 2516-2522.

14. Schrocksnadel K, Wirleitner B, Winkler C, Fuchs D (2006) Monitoring tryptophan metabolism in chronic immune activation. Clin Chim Acta 364: 82-90. 
Citation: Eyraud D, Granger B, Zahr N, Charlotte F, Bardier A, et al. (2015) Measurement of Indoleamine 2, 3 Dioxygenase Activity in Colorectal Cancer: A Controlled Group Study. J Clin Cell Immunol 6: 374. doi:10.4172/2155-9899.1000374

Page 8 of 8

15. Cavia-Saiz M, Muniz P, De Santiago R, Herreros-Villanueva M, GarciaGiron C, et al. (2012) Changes in the levels of thioredoxin and indoleamine-2,3 - dioxygenase activity in plasma of patients with colorectal cancer treated with chemotherapy. Biochem Cell Biol 90: 173-178.

16. Desborough JP (2000) The stress response to trauma and surgery. Br J Anaesth 85: 109-117.
17. Pellegrin K, Neurauter G, Wirleitner B, Fleming AW, Peterson VM, et al. (2005) Enhanced enzymatic degradation of tryptophan by indoleamine 2,3 - dioxygenase contributes to the tryptophan-deficient state seen after major trauma. Shock 23: 209-215. 